\title{
Deeper than a Collection of Artifacts: Recognition of Experiential Learning for Adults within the Academy
}

\author{
Lorayne Robertson, Wendy Hardman \\ UOIT, Canada
}

\begin{abstract}
This study examines the e-portfolio development process of one cohort of adult applicants to a graduate school in one Canadian province relative to Kolb's theory of how adults learn from experience. The study examines the participants' views of their learning processes when preparing the digital portfolios through their written and video-recorded reflections and work logs. Data also include the transcripts from interviews with the e-portfolios authors during the graduate studies program in order to explore how eportfolio learning processes might be predictive of the skills and knowledge required for study in education and technology at the graduate level. Findings indicate that participants' accounts of their experience can be understood through the lens of Kolb's model. The participants recalled key learning activities aligned with Kolb's model that facilitated their e-portfolio development such as: understanding criteria for the assessment of prior learning (PLAR); the establishment of organizing categories for concepts in the portfolio which led to concept development; and support in reconceptualising adult work experience and community service as learning.
\end{abstract}

\section{Introduction}

This study is an investigation of the process of eportfolio design from the perspective of students who were preparing e-portfolios for prior learning assessment recognition (PLAR) at one graduate school in Canada. Portfolios have many dimensions to consider; they are purposeful, organized collections of related materials. According to Conrad [3], the process of building the portfolio can also be thought of as "a knowledge-building process situated within the postsecondary learning culture" (p. 139) wherein the portfolio itself becomes a learning tool and its construction is pedagogy.

Constructing a web-based e-portfolio adds further dimensions to portfolio design, because it introduces flexible ways for the portfolio author to organize the presentation of material for the portfolio audience. The author can employ navigation tools such as hyperlinks to organize online text, and multi-modal forms of text such as video.

Brown [2] sees another dimension to the e-portfolio because of the "the changing nature of articulating online learning" (p.3). She finds that while paperbased portfolio construction can ask adult learners to evaluate their experience as academic knowledge, the e-portfolio process goes beyond this evaluation to make new learning connections for adult learners in a digital era. She states, "The promotion of continuity between academic, workplace, and web-based learning is critical in today's world" (p.12). She sees that the eportfolio presents new venues for adult learners to augment their reflection and communication, and to begin to evaluate different kinds of learning and learning environments.

The research outlined here explores e-portfolio development with these considerations in mind, examining how participants see and describe linkages, if any, among their workplace experience, life experience, the academy, and web-based learning, as well as how they articulate the possibilities they see 
with e-portfolios compared to paper portfolios organized in binders.

Using E-portfolios as PLAR for graduate schools is an area that, at present, is understudied because it is breaking new ground. PLAR appears to be "primarily" available for undergraduate and college courses rather than graduate studies [11]. One issue is how learning is defined relative to the learning outcomes from courses in the academy rather than as life experience or work experience. Conrad [3] notes that, "Nonformal and informal learning acquired by learners through training, workplace offerings, nonaccredited institutions or simply from life's lessons is generally not recognized for transfer by accredited postsecondary institutions" (p.140). Additional issues in higher education include credential integrity and academic standards [3].

Similarly, Brown [2] notes that digital portfolios showcasing experiential learning have "gained limited recognition among adult educators" (p.3). Low uptake at the graduate level might be attributed to a range of factors such as: lack of faculty and student awareness of PLAR; faculty resistance; concerns about quality assurance; and lack of incentives to engage in PLAR [11].

Despite these forms of resistance, the building of an e-portfolio as PLAR is seen as a source of learning that supersedes a simple credit challenge [3]. In addition, the design of the e-portfolio can offer adult learners an opportunity to consider their life and work experiences as learning that could be recognized by the academy. It is for these reasons that research on adults' perceptions of e-portfolios for PLAR in a graduate school is a topic of interest in higher education.

\section{Purpose}

This study investigates graduate school students' perceptions of the process of building e-portfolios for prior learning assessment and recognition (PLAR). This research is intended to: a) understand the development of the e-portfolio as PLAR process as a learning process as it is articulated by the adult learners/e-portfolio designers; b) to investigate participants' perceptions of the predictive validity of eportfolios as PLAR for graduate school expectations; and c) to gain the students' perspectives on valued supports for adult learners in this process.
For the participants in this particular study, the digital portfolios were created to demonstrate prior learning through a combination of experience and credentials. Students created e-portfolios as recognition of their achievement of a baccalaureate degree equivalency, as established in quality assurance policy in one Canadian province. This study follows the participants as they create their e-portfolios; capturing their voices through video and written recordings as they describe and reflect on their process and results. This study includes the portfolios themselves as data sets.

Participants were also interviewed after their acceptance into the graduate program and during their program of study because this research seeks also to capture the participants' perceptions of the PLAR eportfolio process relative to their experiences as learners in a graduate program. Wihak [11] in a Canadian Council on Learning report on PLAR in Canada, finds that, "The achievement of PLAR credits appears to have predictive validity for ability to engage successfully with and persist with post-secondary learning" (p.ii). One of the purposes of this research then, is to gain an understanding of any elements of the e-portfolio PLAR process that have the potential to support the learning skills needed in a graduate program, and support earlier findings regarding the predictive validity of the PLAR process.

At the present time, little is known about how to support adult learners with their e-portfolio development for PLAR, so the role of the support systems is also a topic of investigation in this research.

There is a need also for research that examines how e-portfolios are assessed. Wihak [11] identifies that, "We have no research comparing the effectiveness and efficiency of different methods used in conducting PLAR assessments" (p.iv). In particular, she cites gaps in the research of the understandings of how learners change their conceptualizations of reflection, learning and epistemology through their participation in PLAR. Conrad [3] reports that assessors at her institution look for a $60 \%$ overlap between the learning outcomes of the institution and the e-portfolio for PLAR purposes. This study considers some of these gaps and current issues in Canadian research on e-portfolios for PLAR. 


\section{Theoretical perspectives}

The PLAR e-portfolios in this study were introduced in a graduate school, which is an adult education program. Because the present era requires continuous skill development in both the academy and the workplace, adult learning is becoming increasingly focused on the individual learner's development of capacity for learning how to learn. Kolb presents a model of the process of adult learning which focuses on experiential learning [6] or the key role that experience plays in learning, (as opposed to, for example, a focus on cognition or behaviour). According to Kolb's experiential learning theory (our italics), learning is a process that does not necessarily happen from experience alone, but it is a process where knowledge is created when experience is thought about or considered. For this to happen, the experience needs to be recalled and considered in the context of learning [5]. According to Kolb, learning can begin in multiple ways. One possible progression is to begin with a Concrete Experience which forms the basis for the Reflective Observation stage where the adult learner reviews what has been experienced and reflects on it. A third stage could be one of Abstract Conceptualization where the adult learner thinks about learning from the experience, assimilates and distills this learning, and makes connections and decides on actions to take [6]. At the fourth step, Active Experimentation, the adult learner tests what has been learned by applying it in new situations, using the learning as a guide for new experiences. In other words, the experiential learning is transformed at the stages of abstract conceptualization and active experimentation [5]. Kolb's theory is particularly relevant to this study because the adult learners were attempting to transform their experience as learning.

A second area of research that underpins this study is the use of the e-portfolio. Portfolios may have different formats and purposes, and some are developed as demonstrations of accomplishments or achievements. Whether the portfolio is image-based or text-based, different types of portfolios share similarities [8]. Generally, portfolios are ordered collections of artifacts selected by the portfolio's author to demonstrate the acquisition of knowledge, skills, and achievements over time. Portfolios can fulfill multiple purposes: they may demonstrate learning for self-assessment or evaluation; they may provide an organized presentation of experience, education, and research for career and credentialing purposes; or they may be used for purposes of PLAR. Portfolios can also allow authors to share teaching philosophies and could be used in departmental reviews, self-studies, and accreditation processes [8]. In the case of the study presented here, the participants engaged in the portfolio process toward a credentialing purpose which Conrad [3] describes as a "high-stakes assessment portfolio use" (p. 148).

Portfolios may have a multiplicity of formats, such as an artist's collection of paintings or sketches; a musician's CD or video clips; a text-based portfolio; or a digital portfolio. E-portfolios, however, not only help to organize the content; they also allow the author to provide a mix of multi-modal content that can combine text, audio, video and images [1]; and allow that content to be presented in a manner that is easily accessible to the portfolio's audience.

Digital portfolios open a vista of opportunities for self-expression. According to Abrami and Barrett, "The potential of EP's [electronic portfolios] are nothing short of revolutionary as the dramatic expression of the possibilities of e-learning from cradle to grave" (p. 2). They suggest that the e-portfolio designer has an opportunity to "allow the viewer to form a direct impression of that work without having to rely on the judgement of others. EP's [e-portfolios] tell a story both literally and figuratively by keeping a temporal and structural record of events" (p. 2) [1].

Conrad [3] reports reasons why e-portfolios can alienate assessors; however, noting that some assessors find paper portfolios easier to assess. In addition, there is the possibility that the e-portfolio's emphasis on the affordances of the digital technologies might potentially distract attention from the content of the portfolio, which she terms, "favouring form over content" (p. 149).

A further important consideration is that eportfolios can provide indicators of success beyond credentialing that may be realized through an eportfolio design process including: evidence of moving from teacher to learner-centred conceptions of teaching and learning; and evidence of participants' use of inquiry, problem-solving, and more collaborative methods of learning. Therefore, a third consideration with respect to theoretical foundations is how the design of the e-portfolio can be a knowledge-building process and make new learning connections [3]. It has 
been suggested also that e-portfolios augment connections for the learner among workplace experience and learning in a digital era [2].

In the preparation of an e-portfolio, students must not only decide on artifacts to include and how to design the portfolio, but they must also consider how to organize the portfolio to match the needs of an employer or an assessor. This applies to PLAR portfolios, also. At Athabasca university, students creating e-portfolios for PLAR for credit challenge purposes are expected to research the program and the course outcomes and create a "very targeted and precise document" (p. 148) [3].

In addition to planning and designing the portfolio for recognition of its content for evaluation, designers of e-portfolios also need to make multimedia creation decisions which include considerations of how to design and project their learning so that it will be wellreceived and understood by their audiences.

Another theoretical consideration is how work and life experience can be recognized and acknowledged as learning in the e-portfolio. While portfolios have been shown to address multiple purposes, at the present time, little is known about how adults can capture their work experience and reconceptualise this as "learning" in a portfolio. One distinctive type of portfolio, an experiential learning portfolio, has been defined by Brown in this way, "The experiential learning portfolio in adult higher education, unlike the academic or teaching portfolio, is a purposeful compilation of document-supported descriptions of learning outcomes acquired from professional and personal experiences" (p. 2). She finds that experiential learning e-portfolios work well in the current era because they allow adults to capture their learning and experiences from multiple venues and then present this learning using multiple modalities [2].

In summary, e-portfolios have the potential to deepen learning [1], [3] and help adult learners make connections between work experience and the academy [2]. These theoretical conceptualizations point toward the possibility that the portfolio building process can support students in realizing deeper understandings about learning; make connections among work experience, learning and technology; and assist students with realizing and articulating new understandings about the e-portfolio design process as both a form of authentic assessment and as learning.
These theoretical considerations led to the following two research questions:

1) How closely do the PLAR e-portfolio designers in this study follow an adult experiential learning cycle pattern in their eportfolio development? and

2) What can be learned about how portfolios both document and generate learning?

\section{Methodology}

The methodology for this study is qualitative and phenomenological in its orientation. The data set includes the graduate students' PLAR e-portfolios; their reflections on the development of the digital portfolios; and post-design interviews with the participants during their graduate studies.

The interviews were transcribed and sent to the participants for verification. Next, the interview transcripts were analyzed using blind review by the research team who used open coding to determine categories of responses [7]. The coding was then reviewed by the researchers together to determine general categories of findings. Next, all of the data were organized into the agreed-upon categories with the researchers working together and modifying the categories through discussion and using the constant comparative method [7]. Both axial coding for the linkages and selective coding of key categories were employed. In addition, the research team considered these emergent themes in the data relative to key issues raised in the literature: the role of technology; indications of deeper learning and connections; and participant identification of scaffolding strategies and supports that were helpful to them in the e-portfolio development process.

At the next stage of analysis, these data were examined using a more direct content analysis [7], using Kolb's learning cycle which is a model of transforming experience into learning [5], [6]. According to Kolb's experiential learning cycle [5], learners move through stages of the cycle, not in a predetermined order, but based on their learning style. The stages are: concrete learning; reflective observation; abstract conceptualization; and active experimentation. Adult learners approach learning differently and Kolb has identified four learning styles associated with this experiential learning theory: diverging, assimilating, converging and 
accommodating [6]. Based on learning style and the requirements of the task, adult learners approach tasks, theorize about them and then apply their theories to test out applications, resulting in either reinforcement or change in their ensuing actions [6]. In the research described here, all of the data were analyzed based on Kolb's experiential learning theory framework [5].

\section{Findings}

The participants indicated in their e-portfolios and interviews that they had different credentials and experience, with varying years of work experience in education or digital technologies as well as multiple community service and personal interest areas. Those who had less formal schooling found it difficult initially to identify activities in their work and life experience that best demonstrated learning and they described the e-portfolio creation as a process in recognizing learning from experience. Their voices are reported in the section that follows. (The genders of the participants are masked in the reporting by assigning pronouns arbitrarily.)

Overall, the findings from this study indicate that the participants' accounts of designing an e-portfolio as PLAR for an undergraduate degree can be understood through the lens of Kolb's experiential learning theory [5]. The participants recalled key steps that facilitated their e-portfolio development that align with Kolb's model. One area of focus for them was concrete learning. Some participants were very concerned with: 1) the platform they would use for the internet-based portfolio, and 2) how they could correlate their learning and experience to match the defined competencies of an undergraduate degree for the assessment of prior learning. Many of the participants also focused on reflection. The stage of abstraction, described as abstract conceptualization by Kolb, was described by the participants as a very challenging process they undertook in order to organize their experience into learning. There was also evidence of the application and transformation of learning in the data as these adult learners reconceptualised their work experiences and community service under learning competencies and learning concepts.

In the findings which are outlined in this paper, examples of participants working at different stages of Kolb's cycle of experiential learning are presented. Kolb's model is not intended to be sequential, although some of the participants appeared to move through the stages of the cycle in the order that they have been presented here.

One stage in Kolb's theory is that of Concrete Learning: two main concerns were evident for some participants as they began their e-portfolio development and these were the desire to envision what their portfolio would look like, and also how they would establish equivalency to a bachelor's degree. The questions and concerns at this stage were related to these concrete issues. One student stated that the big aspect for him was, 'What platform should I build my portfolio in or on... What tool should I use?" Another recalls asking himself, "How do I turn professional experiences that I've lived into something tangible I can reproduce on a webpage?" Another stated that his concern was, "How do I use this work to showcase myself, not just as a teacher, but as a human being?" Another described the first step this way, "How am I going to display this and in a way that makes sense?"

There were many comments in the data about choosing a web-based portfolio platform because not all of the applicants had experience with designing a web-based presence. The participants had free rein; as one explained, "We chose our own platform and then built it." Another commented, "Even if you're an accomplished professional, which I consider myself to be, it doesn't matter. You still have that crisis of confidence when you get into an unfamiliar environment."

Some participants started with one tool and changed their choice as they worked with it and discovered limitations they were not willing to tolerate. There were a number of creative solutions for those with less experience with webpages such as enlisting the help of a tech-savvy friend. Members of the cohort supported each other at this phase. One stated, "I don't know what I would have done without my technical buddy. I think that [the online design] would've weighed so much more heavily on me."

The second challenge for those participants working at a concrete stage was to begin to pull together their artifacts and credentials in order to show that their accumulated work and life experience could be equated with the learning from an undergraduate degree. For this stage of the process, the advisor provided a list of the baccalaureate degree competencies that had been established by a council of university vice-presidents. The participants referred to 
these as "the OCAV competencies." In describing this part of the process, one participant acknowledged that they were starting from a place of "not knowing", stating, "It was our first exposure to OCAV equivalencies. It wasn't a familiar type of exercise to try to grab your life's work and match it up with the equivalencies. It did take a while, so it wasn't a one week process." One of the participants designed a chart that included her artifacts and how each of these artifacts would meet the competencies. Others found this type of concrete model to be very helpful at the initial stages.

Other concrete learning strategies employed by the graduate advisor at the beginning of the portfolio development included reading and discussing scholarly articles about portfolios/e-portfolios, discussing the baccalaureate degree competencies, and reviewing sample e-portfolios. Participants also worked individually in these directions. One recalled, "I immediately looked for samples of e-portfolios at educational institutions to try to model and get some familiarity because it was just this big question mark."

The advisor met with the students as a group and individually, and the participants recalled a combination of individual and group work which helped them lay these foundations. Concrete learning activities also included regularly-scheduled meetings where they gained insights from each other and their advisor. Initially, this was not easy for all students, with one reporting "...discussion with peers and review of external literatures, we slowly tried to grasp that. But I find it very theoretical." This shows that the strategies attempted did not resonate with all participants.

A second stage in Kolb's experiential learning cycle is termed Reflective Observation. Participants working at this point in the learning cycle gain understanding from hearing different points of view about ideas and situations, while still relying on one's own thoughts and feelings to form opinions. The participants described reflective activities such as reflections and a learning plan which were built into the e-portfolio process. As one participant describes, "We also had to keep a journal on a weekly basis...and then you would go back and read them. It's almost like I'm giving feedback to myself." Another says, "Reading over what I was writing helped me sort of get over myself and say 'Quit complaining. Quit whining, and start doing'." Not every participant kept the weekly journal, with one reporting that the "weekly" interviews were completed later in the process looking back.

Commenting about the required reflections, one participant said, "The [e]portfolio was the first time I had ever professionally really reflected on how I got where I am today and it was an excellent experience." Another said, "Reflection served as a great benefit because it allowed us to revisit many aspects of our lives and even though we've lived our lives along, sometimes we lose touch of our experiences and how much those could be valued or how they could be weighed in terms of a competency...the professor actually pointed out on numerous occasions that we shouldn't sell ourselves short." This participant also explained how reflection helped with synthesis, saying, "We... discovered the wealth of experiences and the value of these experiences and that we've compiled over time, so again reflection helped to bring that out and it helped to paint a more complete picture of our life's work... Oftentimes the pieces are so fragmented that they can't really come together to complete an easily- or readily-understood whole."

One initial activity that helped the participants to begin the process of reflection and begin to realize the value of their own experiences was peer-to-peer interviews. Participants were asked to interview, transcribe, and report about each other's work and other life experiences. This exercise seemed to be important when reported later by them: one recalls, "The professor asked us to interview somebody else that was in the course and ask them questions about their education, their background, their work background....I think that worked really well because...as we were talking and he was asking me questions, it was coming back to me, I was realizing there were things here I'm missing, things I should add, things about my educational background, that I should add things about projects that I've worked on.." These findings indicate that both ongoing selfreflection activities and shared events were seen by the participants as valuable.

A third learning process stage in Kolb's experiential learning cycle is Abstract Conceptualization. Participants in this study reported both challenges and rewards with activities that were associated with the more abstract concepts. The first concept-related activity that was initiated by the professor was the task of designing a concept map of 
each student's background and experience as a follow up to the peer interviews.

Building a concept map was not a new experience for some, but proved to be a valuable step for organizing their experience and future e-portfolios. The concept maps were mentioned by everyone as being a foundational piece for the e-portfolio. Their comments reveal the effort required; one participant said, "It was a process that I think took a lot of time, but it was valuable. I probably spent half of my development time just on the concept map itself." Another recalls that for him, "the first step was making sense of the OCAV equivalencies and e-portfolio; the next step was to develop this concept map."

Feedback from peers and the advisor was a continuous process of back and forth. One participant described it this way, "We all worked on our own concept map, and then we shared and compared and then discussed them again in a group." Another participant recalled, "[The advisor] was able to give us input individually on our concepts maps, saying 'Well, have you considered this?' and [we would go] off and brainstorm some more."

At this stage of concept development, there were comments from multiple participants about the value of hearing assessments from other students at the weekly gatherings. One reports, "We all kind of split out on our own time and then came back together to discuss, discuss how that process was going for us." Although there was the structure of the weekly meetings, one participant reported that the process did not have sufficient structure and that this participant "found the uncertainty of not having a fixed process sometimes challenging."

The second abstract conceptualization challenge for the participants was the advisor's requirement to choose three or four concepts that would help to anchor or organize the e-portfolios. Deciding on the most appropriate keywords to organize their e-portfolios was a lengthy process. One participant said that he approached it in this way, "I thought, OK. Where have I lived my big chunks of my life? What have I done? ... and I'm going to try to organize around that."

Participants reported struggles and challenges with finding these high-level concepts as organizers. One said, "There was a lot of struggle for like probably three or four weeks." Another said, "I was getting very, very frustrated that I had nothing to show, nothing tangible to show for three weeks of work."
Still another recalled later that, "I put a lot of thought into that." A final participant reported, "That was a bit of a challenging piece because I probably renamed them three or four times."

Two participants reported that they found that the organizing of the portfolio and the selection of the organizer categories were the biggest challenges but the "most important aspect." One compared it to painting a room, stating, "The...organizing up front and the preparation piece was absolutely number one and imperative. To me it's kind of like painting a wall, doesn't take long to paint the wall. All of the time is put into the preparation ahead of time. I think the biggest piece for me, in terms of creating the eportfolio was organizing up front."

While in this organizing process, some of the participants also incorporated an awareness of audience, stating, "That was how I envisioned that in terms or organization, so if someone came to view my portfolio...they were narrowing in on one topic area, they could see the linkages ...they could go and read my post baseline assessment, they could read the reflection...and view the artifacts themselves."

The stage of organizing their learning across key topics or concepts was reported as either challenging or significant for all participants, and was identified as a key stage of struggle in the design of the e-portfolio. One participant found that the selection of the constructs was so powerful that they became, "imprinted into his subconscious" so that he could draw on these schemas in the future. In the final analysis, most e-portfolio designers chose three or four main concepts such as: learning/leadership, communication, digital technology, curriculum and other similarly broad concepts as portfolio organizers.

The researchers determined that activities characterizing the Active Experimentation stage in Kolb's cycle might be characterized as: a) applications of learning to new situations; $b$ ) testing learning in new contexts and scenarios; and c) evidence of transformed or changed thinking about learning and pedagogy. Evidence of learning was articulated by multiple participants with comments such as: "I think I came to an understanding that you could marry experiential learning to formal learning much more readily that I would have believed possible prior to this experience."

Critical thinking was also evident. One of the provincial competencies defining the outcomes for a baccalaureate degree describes a candidate's grasp on 
the breadth and depth of knowledge in a field. One of the e-portfolio participants challenged what appears to be a pre-determined knowledge field in an era where the knowledge base is continuously changing. She noted that, "It is up to me to be...finding out what's the latest technology and how to apply that new technology and...use that for the next project while we're still working on today's." This candidate also took her understandings of teaching and learning from a curriculum mapping project in which she had been involved and applied this learning in a metacognitive sense to how she was learning in the e-portfolio design process, and working toward outcomes.

Another participant found that the design of the eportfolio was reinforcement of learning about concepts to which she had been introduced previously. She reconsidered course work on authentic assessment and then reflected that the e-portfolio experience had helped her to "learn deeper." She said that the eportfolio design had been such a powerful experience that she could recall the steps vividly and analyze the degree competencies even months later. She said that it helped her to formulate thoughts about teaching and learning that, prior to this experience, had not been conscious thoughts.

These descriptions of deeper learning were echoed by other participants. One explained that it was helpful to begin to place learning experiences "within certain theories" and the combination of acquiring learning theory and reflecting on experience in the e-portfolio process had worked well for him. This participant was also a college professor. He described his reflection and e-portfolio design in this way, "[as] looking at what you have done using different lenses definitely, but also thinking about it at a deeper level and what it not only means to your students but also means to you as a teacher and how you can develop further...It has really helped. I understand my students better and my role in the classroom has changed...I have changed assignments and lessons in the classroom because of what I have learned."

In summary then, the study participants as eportfolio designers provided evidence of a more conscious consideration of themselves as learners and critical thinkers, and how they could reconceptualise their experience as learning. Several participants were able to identify situations where they are now applying this new learning to their present roles in education.

\section{Conclusion}

One of the purposes of the study that is described here was to determine whether or not Kolb's experiential learning cycle would be helpful in understanding how adults participating in an eportfolio as PLAR process remembered the process and its impact on their views of teaching and learning. As researchers, we found that this theory helped provide a lens for analysis that allowed us to dig deeper into the participants' portfolios and reflections. Participants articulated their understandings of experience as learning, and how they felt betterenabled to use this understanding as future learners, teachers, and curriculum designers.

For adult learners, the process of changing viewpoints might happen suddenly in moment of realization, or it can happen over time with a structured learning process [10]. Through participation in the eportfolio process, most of the participants indicated that their views of experience as learning changed gradually. They said that the process was, at times, an uphill struggle as they worked with new concepts and understandings. As a result of this process, however, they were able to recall many key aspects in the design of the e-portfolio, indicating that this learning had been significant for them. Deep learning in itself may not be transformative; according to Merriam et al., a transformative learning process requires "experience, critical reflection, reflective discourse, and action" (p. 134) [10]. This discourse can be between two persons or in groups, but this discourse in a formal education environment needs to be facilitated so that it occurs in an environment where other adults listen with empathy but not judgement. The action component associated with application may be either a change or a reinforcement of a previous action with renewed understandings. There was evidence in this study that the e-portfolio participants underwent a change in their thinking as a result of the e-portfolio process and considered this learning to be significant.

Through this study, the participants and the researchers came to new understandings of how eportfolios can both document and generate learning. Although much more research is needed in this area, early indications from this study show that the adult learners can identify and recall key steps of grasping concepts during the e-portfolio design process that prompted them to deepen their reflection and learning 
and consider how to apply this learning in new contexts.

One of the identified gaps in Canadian research is research studies that help to explain how learners can change their conceptualizations of reflection, learning and epistemology through participation in PLAR [11]. In the study reported here, an analysis of the interviews reveals that the participants could reconceptualise experience as learning that could be recognized by the academy. They could recall key activities in the creation of e-portfolios, and their reactions to both familiar and unfamiliar concepts in the e-portfolio design process indicated a deep engagement with learning that could be applied to their future classrooms. Perhaps even more importantly, the participants described the e-portfolio design process itself as learning. As one participant described the process, it was "much deeper than a collection of artifacts."

\section{References}

[1] Abrami, P.C., \& Barrett, H. (2005). "Directions for Research and Development on Electronic Portfolios" Canadian Journal of Learning and Technology. 31 (3). (113). Retrieved $\quad 2013 \quad$ February, @ http://cjlt.csj.ualberta.ca/index.php/cjlt/article/view/92/86http $\% 3$

[2] Brown, J. (2011). "Dwell in possibility: PLAR and ePortfolios in the Age of Information and Communication Technologies". International Review of Research in Open and Distance Learning. 12 (1). 1-23. Retrieved March, 2013 @ Http://www.irrodl.org/index.php/irrodl/article/view/917

[3] Conrad, B. (2011). Building knowledge through portfolio learning in prior learning assessment and recognition. The Quarterly Review of Distance Education. 9 (2).139-150.

[4] Cresswell, J. (2013). Qualitative inquiry in research design: Choosing among five approaches. Thousand Oaks, CA: Sage.

[5] Kolb, D. (1984). Experiential Learning: Experience as the Source of Learning and Development. Englewood Cliffs, NJ: Prentice-Hall.

[6] Kolb, D., Boyatzis, R., \& Mainemelis, C. (1999). Experiential Learning Theory: Previous Research and New Directions in R. J. Sternberg and L. F. Zhang (Eds.), Perspectives on cognitive, learning, and thinking styles. NJ: Lawrence Erlbaum, 2000. Retrieved Oct, 2013 @ http://www.d.umn.edu/ kgilbert/educ5165-

731/Readings/experiential-learning-theory.pdf
[7] Lichtman, M. (2012). Qualitative research in education: A user's guide. $3^{\text {rd }}$ ed. Los Angeles: Sage

[8] Lorenzo, G., \& Ittelson, J. (2005). An overview of EPortfolios. EDUCAUSE. Advancing learning through IT innovation. Retrieved February, 2013 @ http://net.educause.edu/ir/library/pdf/eli3001.pdf

[9] Machala, D. (2009). E-portfolio for recognition of prior learning assessment in continuing education for librarians in Croatia. INFuture 2009: Digital Resources and Knowledge Sharing. p.565-574. Retrieved March, 2013 @ http://infoz.ffzg.hr/INFuture/2009/papers/6-

07\%20Machala,\%20D.,\%20E-

portfolio\%20for\%20Recognition\%20of\%20Prior\%20Learnin g\%20Assessment.pdf

[10]Merriam, S., Caffarella, R., \& Baumgartner, L. (2007). Learning in Adulthood: A Comprehensive Guide. San Francisco: Jossey-Bass.

[11] Wihak, C. (2006). "State of the field review. Prior learning assessment and recognition (PLAR)." Canadian Council on Learning Report. Retrieved March, 2013 @ http://www.ccl-

cca.ca/pdfs/StateOfField/PLARfinalreportMarch26E.pdf 